\section{A Mammalian Peptidase specific for the Hydrolysis of $N$-Terminal $\alpha$-L-Glutamyl and Aspartyl Residues}

THe histochemical visualization of a calcium activated $N(\alpha-$ - -glutamyl $) \beta$-naphthylamide-cleaving activity has been described in an earlier publication ${ }^{1}$. Hydrolysis of $N(\alpha-\mathrm{L}$-aspartyl $) \beta$-naphthylamide has now been observed histochemically in sites identical to those described for $N(\alpha$-L-glutamyl $) \beta$-naphthylamide (for example, guinea pig pancreatic duct epithelium and islets of Langerhans and human and rat glomeruli) in the presence of the optimal concen. tration of the activating ion, calcium. The above tissue section localizations of the enzymatically catalysed hydrolysis of the $\alpha$-L-glutamyl and $\alpha$-L-aspartyl substrates are distinct from those seen with other $\beta$-naphthylamide substrates in the presence of calcium ions.

An enzyme having the characteristics noted here, aminopeptidase $A$, has been partially purified from rat kidney by the following method. The microsomal fraction derived from sucrose or potassium chloride homogenates of rat kidneys was resuspended in $0.001 M$ tris(hydroxyamino)methane buffer at $p \mathbf{H} 7 \cdot 5$. The particulate suspension was subjected to digestion by a mixture of trypsin and chymotrypsin. Centrifugation of the digest at $100,000 \mathrm{~g}$ gave a particulate fraction containing essentially all the aminopeptidase $A$ activity and was devoid of significant activity toward glycyl, L-leucyl, $\alpha$-L-glutaminyl, DL-alanyl, or DL-phenylalanyl- $\beta$-naphthylamide.

Parallel calcium ion activation of $N(\alpha-\mathrm{L}$-glutamyl $)$ $\beta$-naphthylamide and $N(\alpha$-L-aspartyl) $\beta$-naphthylamide is apparent from the results given in Table 1 .

Table 1. Liberation of $\beta$-NAPHTHYLAMiNe (M $\mu$ MOLES/MIN./MGM.

\begin{tabular}{|c|c|}
\hline & dditions to incubation \\
\hline & None \\
\hline & $0.001 \mathrm{M} \mathrm{CaCl}_{2}$ \\
\hline & $\begin{array}{l}0.01 M \mathrm{CaCl}_{2} \\
0.02 M \mathrm{CaCl}^{2}\end{array}$ \\
\hline & $\begin{array}{l}0.01 M \text { Ethylene- } \\
\text { diamine tetraacetate }\end{array}$ \\
\hline & 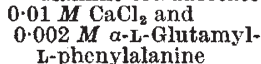 \\
\hline
\end{tabular}
ENZYME)

\begin{tabular}{cc}
\multicolumn{3}{c}{ Substrate } \\
$\alpha-\mathbf{L}$-Glutamyl- $\beta-$ & $\alpha-\mathbf{L}$-Aspartyl- $\beta-$ \\
naphthylamide & naphthylamide \\
27 & $3 \cdot 3$ \\
55 & $9 \cdot 2$ \\
65 & 11 \\
62 & 11 \\
$3 \cdot 3$ & $0 \cdot 3$ \\
& \\
20 & $2 \cdot 2$
\end{tabular}

*Incubation solution: Enzyme, 0.06 mgm. dry weight; substrate, $0.41 \mathrm{mgm}$. $\alpha$-L-glutamyl- $\beta$-naphthylamide or $0.39 \mathrm{mgm}$, $\alpha$-I -aspartyl$\beta$-naphthylamide; fast garnet GBC, $0.5 \mathrm{mgm}$.; in $3 \mathrm{ml} .0 .1 \mathrm{M}$ tris(hydroxyamino)methane-maleate buffer, $p \mathrm{H}_{7 \cdot 0}, 37^{\circ} \mathrm{C}$. The reaction was stopped after $10 \mathrm{~min}$. by the addition of $1 \mathrm{ml}$. 10 per cent 'Tween $20^{\prime}$ in $1 M$ acetate buffer, $p \mathbf{H} 4 \cdot 2$. After 30 min. absorbance at $525 \mathrm{~m} \mu$ was determined.

Disodium ethylenediamine tetraacetate and $\alpha-\mathrm{L}$ glutamyl-L-phenylalanine produced an inhibitory effect on the hydrolysis of the aspartyl substrate equivalent to that produced on the glutamyl substrate. The inhibition by $\alpha-\mathrm{L}$-glutamyl-L-phenylalanine was found to be of a competitive nature. No effect on hydrolysis was afforded by L-leucinamids, L-leucylglycine or glycyl-glycine $(0.002 M)$. The dipeptides $\alpha$-L-glutamyl-L-phenylalanine and $\alpha$-L-aspartyl-L-arginine were defined as substrates for aminopeptidase $A$ by chromatographic identification of constituent amino-acids of each dipeptide following incubation with the enzyme. No hydrolysis of $N(\alpha-D$-glutamyl $) \beta$ naphthylamide, $N\left(N^{a}\right.$-benzoyl- $\alpha$-L-glutamyl) $\beta$-naphthylamide or $N$-carbobenzoxy- $\alpha$-L-glutamyl-L-phenylalanine was observed in the presence of high concentrations of aminopeptidase $A$.

Strong evidence that the hydrolysis of both the $N(\alpha-\mathrm{L}$-aspartyl $)$ - and $N(\alpha-\mathrm{L}$-glutamyl $) \beta$-naphthylam- ide substrates is catalysed by the same enzyme is afforded by the identical effects of activator and inhibitors on the hydrolysis of these substrates and the identical histochemical localization obtained with both. Moreover, the maximum velocity determined by the method of Lineweaver and Burk using an equimolar mixture of naphthylamide substrates was found to lie between the maximum velocities of the individual substrates, again attesting to the fact that only one enzyme is involved in the hydrolytic reactions.

The absence of hydrolysis of $N(\alpha$-D-glutamyl $) \beta$ naphthylamid $\ni$ and $N\left(N^{\alpha}\right.$-benzoyl- $\alpha$-L-glutamyl $) \beta$ naphthylamide in both the histochemical and bio. chemical systems and of $N$-carbobenzoxy- $\alpha$-L-glutamyl-t-phenylalanine in the biochemical system indicates that aminopeptidase $A$ is stereospecific and exhibits primarily exopeptidase activity.

The biochemical data confirm the existence of the histochemically defined peptidase having a relative specificity for $N$-terminal L-dicarboxylic amino-acids. For convenience and clarity of nomenclature this enzyme is referred to as aminopeptidase $A$ (acid $\alpha$-amino peptidase) to distinguish it from classic leucine amino peptidase ${ }^{2}$ and enzymes hydrolysing acidic omega amino ${ }^{3}$ and non-acidic $\alpha$-amino-acid $\beta$-naphthylamides 4 .

Pig kidney and duodenum are good sources of aminopeptidase $A$ and further investigations to obtain a more purified preparation from these sources are in progress. A report of these studies as well as a detailed account of the kinetics of aminopeptidase $A$ activity, its application as an end group reagent, the steric and chemical limits of specificity of the enzyme toward synthetic substrates and procedures for the syntheses of these substrates will be the subject of future communications.

\author{
G. G. Glenner \\ P. J. McMrllan * \\ Laboratory of Experimental Pathology, \\ J. E. Folk \\ Laboratory of Biochemistry, \\ National Institutes of Health. \\ Bethesda, Maryland. \\ * U.S. Public Health Service Post-Doctoral Fellow in Histochem- \\ istry. \\ ${ }^{1}$ Glenner, G. G., and Folk, J. E., Nature, 192, 338 (1961). \\ ${ }^{2}$ Smith, E. L., and Spackman, D. H., J. Biol. Chem., 212, 271 (1955). \\ ${ }^{3}$ Glenner, G. G., Folk, J. E., and McMillan, P. J., J. Histochem. \\ Cytochem. (in the press). \\ 4 Folk, J. E., and Burstone, M. S., Proc. Soc. Exp. Biol. Med., 89, 473 \\ (1955).
}

\section{Adrenal Glucose-6-Phosphatase : Altera- tions in Intracellular Distribution induced by Treatment with Adrenocorticotrophic Hormone}

Haynes et al. ${ }^{1}$ have proposed a mechanism of the action of adrenocorticotrophic hormone (ACTH) on the adrenal gland in which glucose-6-phosphate (G-6-P) plays a most important part. The increased rate of production of G-6-P, arising from the activation of phosphorylase by ACTH to produce increased quantities of glucose-1-phosphate and the subsequent conversion of the glucose-1-phosphate to G-6-P by phosphoglucomutase, results in an increased metabolism of G-6-P by oxidation to 6-phosphogluconic acid. This oxidation produces reduced triphosphopyridin nucleotide (TPNH) and the TPNH serves as a source of energy for various steps in the produotion of steroids ${ }^{2}$. However, G-6-P may also be metabolized 